\title{
The Utility of Preoperative Neuromonitoring for Adolescent Idiopathic Scoliosis
}

\author{
SOHRAB VIRK, MD, MBA, ${ }^{1} \mathrm{JAN}$ KLAMAR, MD ${ }^{2}$ ALLAN BEEBE, MD, ${ }^{2}$ DEBABRATA GHOSH, MD, ${ }^{3}$ \\ WALTER SAMORA, MD ${ }^{1,2}$ \\ ${ }^{I}$ Department of Orthopaedics, The Ohio State University, Columbus, Ohio, ${ }^{2}$ Department of Orthopedic Surgery, Nationwide Children's Hospital, Columbus, Ohio, \\ ${ }^{3}$ Department of Neurology, Nationwide Children's Hospital, Columbus, Ohio
}

\begin{abstract}
Background: Intraoperative neuromonitoring is well established and widely used to assist in completing corrective surgery for adolescent idiopathic scoliosis (AIS) safely. The role of preoperative measurement of somatosensory evoked potentials (SSEPs) and/or transcranial magnetic stimulation (TMS) to determine if there is transpinal pathology, however, is not clear. We sought to determine if preoperative SSEP and/or TMS measurement provided clinical benefit to patients with AIS.

Methods: A review of medical charts between 2010 and 2012 was conducted for patients undergoing surgery for scoliosis. Patients with diagnoses other than AIS were excluded. Patients with incomplete preoperative or intraoperative data were also excluded. Relevant clinical information such as age, sex, number of levels fused, and major Cobb angle were recorded. Preoperative neuromonitoring measurements and intraoperative neuromonitoring results were reviewed by an attending neurologist. Any instance in which an intraoperative surgical plan or neuromonitoring result interpretation was influenced by preoperative results was recorded. Further imaging obtained based on preoperative results was noted. Any acute neurologic complication such as paralysis was noted.

Results: Eighty-one patients met inclusion criteria (64 female, 17 male). Average age was 15 years $( \pm 1.92)$. Major Cobb angle at preoperative evaluation averaged 57.5 degrees ( \pm 10.81 degrees). Ten patients had abnormal preoperative SSEP/TMS results. There were no changes in protocol during intraoperative neuromonitoring based upon preoperative neuromonitoring findings. No additional imaging was required for patients with abnormal preoperative neuromonitoring results. There was no statistically significant difference in preoperative Cobb angle between the group of patients with abnormal preoperative neuromonitoring and those with normal baseline testing.

Conclusion: Preoperative SSEP/TMS measurement prior to corrective surgery for AIS has limited utility. There were no instances in which a patient's clinical course was improved by testing. We recommend against routine use of preoperative SSEP/TMS testing for AIS patients requiring corrective surgery.
\end{abstract}

Other and Special Categories

Keywords: adolescent, idiopathic scoliosis, neuromonitoring, SSEPs, TMS

\section{INTRODUCTION}

Adolescent idiopathic scoliosis (AIS) is a coronal curvature of the spine that affects approximately $1 \%$ to $3 \%$ of the adolescent population. ${ }^{1}$ Of these patients, a small percentage $(0.3 \%$ to $0.5 \%)$ progress toward operative intervention. ${ }^{2}$ For patients requiring surgery for AIS, intraoperative neuromonitoring has become the standard of care to monitor for any neurologic injury that might occur during correction of the spinal deformity. ${ }^{3-6}$

The utilization of preoperative somatosensory evoked potential measurements (SSEPs) or transcranial magnetic stimulation (TMS), however, has not been widely adopted by surgeons treating patients with AIS. The benefit of these exams is to exclude an intraspinal abnormality that may be causing the progression of a spinal curve. ${ }^{7,8}$ The preoperative findings could also provide a baseline for testing that could be used intraoperatively to identify abnormalities in neuromonitoring arising from the corrective surgery. Previous studies have not shown any significant clinical benefit from preoperative measurements of posterior tibial SSEPs and have shown that posterior tibial SSEPs are not affected by Cobb angle. ${ }^{8,9}$

The goal of our study was to determine if preoperative measurements of TMS or SSEPs combined might help predict intraspinal pathology for patients originally diagnosed with AIS. We also hoped that preoperative neuromonitoring would 
give baseline values for SSEP/TMS, which might help us during intraoperative neuromonitoring. We hypothesized that there would be a portion of patients with abnormal preoperative results that might benefit from further imaging to determine if intraspinal pathology was present. Furthermore, we sought to learn whether preoperative defects in SSEP/TMS measurements might benefit clinicians during interpretation of intraoperative neuromonitoing results.

\section{MATERIALS AND METHODS}

A review of clinical information was performed on patients undergoing corrective surgery for scoliosis with approval from our home institution's Institutional Review Board. We used our institution's data warehouse in order to find patients with Current Procedural Terminology Codes (CPT Codes) related to neuromonitoring (CPT 95925 to 95929) as well as International Classification of Diseases (ICD-9) codes related to thoracolumbar fusion. The ICD-9 codes for thoracolumbar fusion included 81.07 (lumbosacral fusion), 81.62 (fusion of 2 or 3 vertebrae), 81.63 (fusion of 4 to 8 vertebrae), and 81.64 (fusion of 9 or more vertebrae). Only those patients for whom both CPT codes for neuromonitoring and ICD-9 codes for thoracolumbar fusion were included were initially analyzed. The time period for this query was 2010 to 2012.

Once this first set of patients was determined, a comprehensive review of each patient's medical chart was performed. All patients with known diagnoses related to neuromuscular diseases, juvenile idiopathic scoliosis, or Scheuermann's kyphosis were excluded. Patients without a complete data set of preoperative and intraoperative neuromonitoring results were also excluded. Only patients without focal neurologic deficits, and with a normal superficial abdominal reflex and right thoracic or thoracolumbar or double major curves were included.

The data collected for patients included within the study were age, sex, preoperative major Cobb angle, levels fused during the operation, neuromonitoring results, and any postoperative complications. The minimum time of follow-up for these patients was 6 months.

Neuromonitoring was performed by specially trained neurophysiologists both before and during the operation. SSEPs and TMS measurements were
Table 1. Demographic information for patients who underwent preoperative neuromonitoring testing.

\begin{tabular}{lc}
\hline Patient Characteristics & Value \\
\hline Sex, no. of patients $(\%)$ & $17(21)$ \\
$\quad$ Male & $64(79)$ \\
$\quad$ Female & $15.00 \pm 1.92$ \\
Average age, years \pm SD & $57.51 \pm 10.8$ \\
Average preoperative Cobb angle, degrees \pm SD & $8-9$ \\
Average no. of levels fused & \\
\hline
\end{tabular}

recorded. Standard techniques were used to measure amplitude and latencies throughout the body. These exams required intubation and sedation for the patient's comfort, as well as to better simulate the operative environment for testing. A Student $t$ test was used to compare the preoperative Cobb angle between the cohort of patients with normal preoperative SSEP/TMS testing compared to those patients with abnormal SSEP/TMS testing.

\section{RESULTS}

Eighty-one patients met all of our inclusion criteria. The demographics for these patients are listed in Table 1. There were 13 patients excluded for the following diagnoses: diskitis, neurofibromatosis, multiple sclerosis, syrinx, revision surgery $(2$ patients), hydrocephalus, congenital scoliosis, spinal cord tumor, juvenile idiopathic scoliosis, and pseudochondroplasia. There were 14 patients excluded because of incomplete preoperative and/or postoperative neurmonitoring results. The majority of patients were female $(79 \%)$ and the average age was 15 years old. As expected, the average preoperative Cobb angle was well above 50 degrees (57.51 degrees) (Table 2). The average number of levels fused was 8 to 9 levels.

There were 71 patients with completely normal SSEP and TSM findings prior to their operation. There were 10 patients with abnormal preoperative SSEP/TSM exams. Eight patients only had abnormal posterior tibial nerve SSEP findings. The abnormal findings are listed within Table 3 . Follow-up for this cohort of patients ranged from approximately 6 months to 6.5 years. There were no instances of neurologic injury for these 81 patients following scoliosis correction surgery.

The average Cobb angle for patients with an abnormal preoperative SSEP/TSM testing was 60.8 degrees ( \pm 10.18 degrees). The average Cobb angle for patients with normal preoperative SSEP/TSM testing was 57.21 degrees ( \pm 10.78 degrees). This 
Virk et al.

Table 2. Comparison between patients with abnormal preoperative neuromonitoring.

\begin{tabular}{lccc}
\hline Patient Characteristics & $\begin{array}{c}\text { Patients with Abnormal } \\
\text { Preoperative Neuromonitoring }\end{array}$ & $\begin{array}{c}\text { Patients with Normal } \\
\text { Preoperative neuromonitoring }\end{array}$ & \begin{tabular}{l}
$\boldsymbol{P}$ Value \\
\hline Age, years \pm SD
\end{tabular} \\
Females, \% & $15.03 \pm 4.28$ & $80.77 \pm 4.28$ & 79 \\
Cobb angle, degrees \pm SD & $60.8 \pm 10.18$ & $57.21 \pm 10.78$ & .71 \\
\hline
\end{tabular}

was not a statistically significant difference $(P=.32)$.

\section{DISCUSSION}

Our findings do not show significant benefit from preoperative measurement of SSEPs or TMS. These exams did not impact the clinical course for any of our patients diagnosed with AIS. Furthermore, for these patients, the same operative intervention was performed irrespective of the preoperative SSEP/ TMS results.

Given the limited clinical utility of preoperative SSEP/TMS testing and the increasing scrutiny on healthcare costs it is unlikely that routine preoperative SSEP/TMSS testing would be reimbursed by third-party payers. ${ }^{10}$ Furthermore, surgery for AIS patients has been estimated to cost approximately $\$ 48900$ per patient. ${ }^{11}$ Any additional costs that do not have proven clinical utility are difficult to justify. The limited clinical information from preoperative testing makes it difficult to justify the risks a pediatric patient is put through during intubation and sedation for preoperative SSEP/ TMS measurements.

SSEP results can fluctuate based on various factors, which makes direct comparison of preoper-

Table 3. Specific abnormal findings for patients during the preoperative neuromonitoring testing. As shown, there was no change in intraoperative neuromonitoring based upon the preoperative findings. None of these patients had additional preoperative imaging.

\begin{tabular}{llc}
\hline Patient & Preoperative Neuromonitoring Abnormality & $\begin{array}{c}\text { Intraoperative } \\
\text { Adjustments? }\end{array}$ \\
\hline 1 & $\begin{array}{c}\text { Decreased amplitude of waveform over left } \\
\text { popliteal fossa }\end{array}$ & None \\
2 & $\begin{array}{c}\text { Decreased amplitude and increased latency over } \\
\text { right lumbar spine }\end{array}$ & None \\
3 & $\begin{array}{l}\text { Increased latency of P37 on right side } \\
\text { Decreased amplitude and increased latency at } \\
\text { right N37 }\end{array}$ & None \\
5 & $\begin{array}{c}\text { Increased latency of N18, N37, P31, N45 on } \\
\text { right side }\end{array}$ & None \\
6 & $\begin{array}{l}\text { Increased latency of N45 on right/left side } \\
\text { Decreased amplitude of N45 on right/left side }\end{array}$ & None \\
8 & $\begin{array}{l}\text { Increased latency of P37 on right/left side } \\
\text { Increased latency of brachioradialis during }\end{array}$ & None \\
9 & MEP & None \\
10 & Increased latency at the Erb point on left side & None \\
\hline
\end{tabular}

Abbreviation: MEP, motor evoked potential. ative versus intraoperative measurements difficult. These factors include blood pressure, temperature of the room, positioning, and the type of intraoperative anesthetic utilized. ${ }^{8}$ Given these factors, it is more than likely that taking baseline SSEP waveforms within the operating room would be more beneficial as compared to using values found in the preoperative testing environment. Furthermore, given the age of these patients, sedation was required for neuromonitoring testing.

There are several important limitations for our study. This was a retrospective review, which is associated with recall/selection bias. The clinical information in this article largely stems from progress notes, operative reports, and radiographs from the electronic medical record, which is only as reliable as the physicians who enter the data into that record. Furthermore, there were 14 patients who had incomplete preoperative and/or postoperative neuromonitoring results, which was a higher number than we expected.

Our study shows results similar to those found previously by Hausmann et al and Shen et al, showing that preoperative testing of TMS/SSEP does not affect the clinical course for AIS patients being treated operatively. ${ }^{7,8}$ Similarly, our findings do not demonstrate any correlation between preoperative neuromonitoring abnormalities and Cobb angle. ${ }^{9}$ Given our results, we would not recommend obtaining preoperative SSEP or TMS measurements for patients with AIS.

\section{REFERENCES}

1. Weinstein SL, Dolan LA, Cheng JCY, Danielsson A, Morcuende JA. Adolescent idiopathic scoliosis. Lancet. 371(9623):1527-1537.

2. Weinstein SL, Dolan LA, Wright JG, Dobbs MB. Effects of bracing in adolescents with idiopathic scoliosis. $N$ Engl $J$ Med. 2013;369(16):1512-1521.

3. Noonan KJ, Walker T, Feinberg JR, Nagel M, Didelot W, Lindseth R. Factors related to false- versus true-positive neuromonitoring changes in adolescent idiopathic scoliosis surgery. Spine. 2002;27(8):825-830.

4. Dawson EG, Sherman JE, Kanim LE, Nuwer MR. Spinal cord monitoring. Results of the Scoliosis Research Society and 
the European Spinal Deformity Society survey. Spine (Phila Pa 1976). 1991;16(8 Suppl):S361-S364.

5. Fehlings MG, Brodke DS, Norvell DC, Dettori JR. The evidence for intraoperative neurophysiological monitoring in spine surgery: does it make a difference? Spine (Phila Pa 1976). 2010;35(9 Suppl):S37-S46.

6. Samdani AF, Bennett JT, Ames RJ, et al. Reversible intraoperative neurophysiologic monitoring alerts in patients undergoing arthrodesis for adolescent idiopathic scoliosis. $J$ Bone Joint Surg Am. 2016;98(17):1478-1483.

7. Hausmann ON, Boni T, Pfirrmann CW, Curt A, Min K. Preoperative radiological and electrophysiological evaluation in 100 adolescent idiopathic scoliosis patients. Eur Spine J. 2003;12(5):501-506.

8. Shen WJ, McDowell GS, Burke SW, Levine DB, Chutorian AM. Routine preoperative MRI and SEP studies in adolescent idiopathic scoliosis. $J$ Pediatr Orthop. 1996;16(3):350-353.

9. Hausmann O, Min K, Boni T, Erni T, Dietz V, Curt A. SSEP analysis in surgery of idiopathic scoliosis: the influence of spine deformity and surgical approach. Eur Spine $J$. 2003;12(2):117-123.

10. Hilibrand AS, Spindler K, O'Keefe RJ. Demonstrating the value of orthopaedic surgery through multicenter trials. $J$ Bone Joint Surg Am. 2015;97(7):e35.
11. Larson AN, Polly DW Jr, Ackerman SJ, et al. What would be the annual cost savings if fewer screws were used in adolescent idiopathic scoliosis treatment in the US? $J$ Neurosurg Spine. 2016;24(1):116-123.

Disclosures and COI: The authors received no funding for this study and report no conflicts of interest.

Corresponding Author: Walter Samora, MD, Department of Orthopedic Surgery, Nationwide Children's Hospital, 700 Children's Dr, T2EA2700, Columbus, OH 43205. Phone: (614) 7223393; Fax: (614) 722-3373; Email: walter.samora@, nationwidechildrens.org.

Published 31 August 2019

This manuscript is generously published free of charge by ISASS, the International Society for the Advancement of Spine Surgery. Copyright (C) 2019 ISASS. To see more or order reprints or permissions, see http://ijssurgery.com. 